\title{
Os conceitos no tratamento da informação arquivística: unidade basilar para a compreensão do conteúdo documental
}

Brígida Maria Nogueira Cervantes

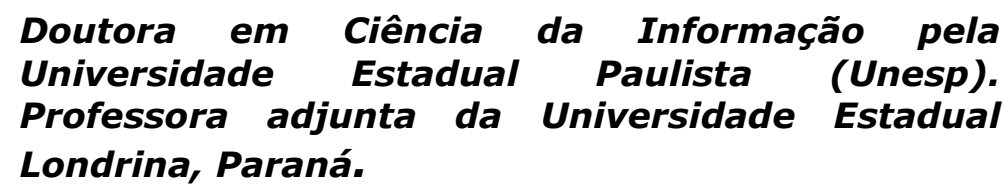

Cynthia Maria Kiyonaga Suenaga

Doutoranda em Ciência da Informação pela Universidade Estadual Paulista (Unesp).

\section{Maria Rosemary Rodrigues}

Mestre em Ciência da Informação pela Universidade Estadual de Londrina (UEL).

http://dx.doi.org/10.1590/1981-5344/3237

A relevância de Paul Otlet e consequentemente da Bibliografia e Documentação na Ciência da Informação evidencia-se a partir do Tratado da Documentação, que desenvolveu a análise do conteúdo dos documentos por meio da extração de termos representativos, que hoje associamos aos conceitos. A importância da identificação de conceitos para o tratamento intelectual da informação consolida-se a cada dia, expandindo seu uso para outras áreas, conforme percebe-se pela aproximação verificada entre Arquivística e Ciência da Informação nos atuais estudos sobre Tratamento Temático da Informação em Arquivos. O objetivo foi evidenciar a relação dos estudos bibliográficos para a representação de conceitos no tratamento intelectual da informação no âmbito da Arquivística. A metodologia utilizada foi a pesquisa exploratória e teve como procedimento metodológico o estudo bibliográfico. Nos resultados verificou-se que atividades de tratamento intelectual da informação na Biblioteconomia e na Arquivística são contempladas pelo Tratamento Temático da Informação, na medida em que são beneficiadas por suas teorias e propostas de 
tratamento documental, com vistas à recuperação da informação, por meio da identificação e representação de conceitos, considerados aqui como unidades do conhecimento e como base do Tratamento Temático da Informação. Nas considerações finais evidenciou-se a importância dos estudos bibliográficos durante o desenvolvimento da Organização e Representação do Conhecimento, quando Paul Otlet menciona que para transmitir uma ideia é necessário identificar os conceitos. Tal visão permanece atual e se fortalece, conforme demonstrado pela associação dos conceitos de classificação e descrição na Arquivística aos processos de Organização e Representação do Conhecimento.

Palavras-chave: Bibliografia. Documentação. Organização e Representação do Conhecimento. Conceito. Tratamento Temático da Informação.

\section{Concepts in Treatment of Archival Information: basic unit for the comprehension of documentary content}

The relevancy of Paul Otlet and consequently of Bibliography and Documentation in Information Science is emphasized on the Treaty of Documentation, that developed the content analysis of the documents through the extraction of representative terms which are currently related to concepts. The importance of identify concepts for intellectual treatment of information consolidate itself each day expanding its use to other fields, as it is identified by the approaching of Archival Science and Information Science by conducting studies on Subject Treatment of Information in archives and their application in archival environment. The objective of the present study was emphasizing the relation of bibliographical studies for the representation of concepts in intellectual treatment of information in the scope of Archival Science. The employed methodology was an exploratory research and its methodological proceeds consist in a bibliographical study. It was verified that activities involving intellectual treatment of information in Library Science and Archival Science are deliberated by Subject Treatment of Information. Insofar as they benefit by its 
theories and documental treatment proposals in order to retrieve information through identification and concepts representation, thus they are considered as knowledge units and base of Subject Treatment of Information. In It was also emphasized the importance of bibliographical studies during the development of Knowledge Organization and Representation, when Paul Otlet mentions that it is necessary identify concepts before convey an idea. Such perspective remains current and reinforce itself as it is demonstrated by the relation of classification concepts and description in Archival Science to the processes in Knowledge Organization and Representation.

Keywords: Bibliography. Documentation. Knowledge organization and representation. Concept. Subject treatment of information.

Recebido em 31.05.2017 Aceito em 30.06.2017

\section{Introdução}

A dificuldade crescente em relação à bibliografia acadêmica, desencadeada pelo aumento da produção de materiais escritos, e a consequente necessidade de pesquisar, identificar, descrever e classificar os documentos, para melhor compreendê-los, levaram Paul Otlet e Henry La Fontaine a criar em 1892 o Instituto Nacional de Bibliografia (INB) (SHERA; CLEVELAND, 1969). A motivação do INB era oferecer uma visão ampla daquilo que existia sobre determinado tema utilizando-se de fichas padrão, tornando a informação bibliográfica registrada em uma espécie de conhecimento modular, que poderia ser aproveitado em outros locais e contextos.

Segundo Rayward (1990) a Documentação foi concebida como um campo de estudo e pesquisa preocupado com as funções que grupos diferentes de instituições realizam e com aquilo que criam ou registram nesse processo, não com as instituições em si. Desta forma os procedimentos da Bibliografia de reunir informações de forma compacta e externa ao livro ampliaram seu objeto para abarcar documentos de outros formatos. Considerando, desta forma, a bibliografia, as bibliotecas, arquivos, museus e um novo tipo de enciclopédia institucional, formado pelas informações compiladas, como a expressão das funções atribuídas ao documento, concebido aqui como tudo aquilo que transporta informação, sobretudo documentos escritos.

A importância da contribuição dos estudos bibliográficos para os fundamentos da Organização e Representação do Conhecimento pela representação de conceitos no tratamento intelectual da informação se 
consolida a partir da fundamental contribuição de Paul Otlet e Henri La Fontaine ao discorrerem sobre a "Documentação", que apresenta, entre outros aspectos, o desenvolvimento de análise mais aprofundada dos conteúdos dos documentos.

A Documentação, como ciência, organiza os documentos considerados como materialização da inteligência humana sobre a realidade. A ela compete selecionar e tratar o conteúdo dos documentos para serem acessados (SANTOS, 2006). Este tratamento, conforme as ideias de Otlet, ocorreria por meio da separação de itens, partes, analisados como fundamentais para transmitir a ideia central de cada documento. Estas partes fundamentais foram mais tarde identificadas como Conceitos.

Os conceitos atuam nas ciências por meio das atividades de examinar, planejar e instrumentalizar os conceitos para atender a demanda de representar, organizar aquilo que se aprende através de diversos meios para vir atender a necessidade de compreensão através da operação conceitual que são: agrupamento, contraste e relação. Percebese que os conceitos auxiliam na organização, possibilitando a sistematização (BARROS, 2016).

Nesse contexto, podemos incluir as pessoas (autor, bibliotecário, trabalhador intelectual, pesquisador, leitor, entre outros) ou organismos diferentes (OTLET, 1937), sendo que a base do tratamento documental possui foco na organização do conhecimento e o conceito destaca-se como a unidade fundamental que viabiliza a compreensão do conteúdo documental em vários níveis, a depender do objetivo de cada análise e do produto que se deseja obter. Para Bräscher e Carlan (2010, p. 173), "Mesmo antes do surgimento da Ciência da Informação, a Biblioteconomia e a Documentação já se ocupavam com a busca de linguagens padronizadas para representação de assuntos".

\section{Desenvolvimento Teórico}

Este aporte teórico busca evidenciar a relação dos estudos bibliográficos para a representação de conceitos no tratamento intelectual da informação no âmbito da Arquivística por meio das seções secundárias: Documentação, Organização e Representação do Conhecimento e Conceitos.

A Documentação tem o elemento intelectual considerado o mais relevante e, para a sua representação em um agrupamento de documentos são necessárias atividades de organização intelectual. A partir disso, na área da Organização e Representação do Conhecimento, o Tratamento Temático da Informação aplicado à Arquivística pode desempenhar a função de organizar a informação e o conhecimento contidos nos documentos. Assim, o conceito é considerado elemento básico para análise e compreensão de objetos informacionais dentro de contextos gerais ou específicos, isso porque, podem ser representados por uma expressão apropriada por meio de instrumento que expõe a 
codificação que forma o conceito. A seguir a primeira subseção Documentação.

\subsection{Documentação}

Quando Otlet desenvolveu a Classificação Decimal Universal (CDU), baseada na Classificação Decimal de Dewey (CDD), acreditava que a classificação era a ferramenta para a organização do conhecimento. Segundo Campos (1994), a Federação Internacional de Documentação (FID) define a Classificação como um método de reconhecimento de relações genéricas, ou de outro tipo, entre itens de informação e, nesse sentido, os conceitos de classificação e organização do conhecimento acabam por ser equivalentes.

O Traité de Documentation de Otlet, ainda que trate predominantemente da Bibliografia, introduz um novo paradigma, no qual o conteúdo do livro (documento) passa a ser o objeto de estudo daquilo que hoje se conhece como Documentação e, de modo mais amplo, Ciência da Informação (CI) (Robredo, 2011). A Documentação aparece como a teoria que se ocupa dos problemas surgidos em decorrência da produção e uso dos documentos de modo geral e da busca por modos de produzilos e utilizá-los.

A Documentação desenvolveu os conceitos de assunto ou conteúdo temático como modo de identificar a unidade intelectual do documento, possibilitando relacionar informações que se encontram dispersas em diferentes documentos, proporcionando a elaboração de novos sentidos. Otlet (1990) buscava fundamentalmente a organização do conhecimento humano quando idealizou o método chamado de Princípio Monográfico, que objetivava extrair informações representativas dos conteúdos dos livros (documentos) e disponibilizá-las sistematicamente de uma maneira integrada por meio de fichas que possuíam as relações entre as informações registradas. Ortega (2011) afirma que o Princípio Monográfico é uma das contribuições mais importantes de Otlet para a Documentação e posteriormente para a CI.

Para Figueiredo (1996), Otlet desenvolveu uma espécie de tecnologia bibliográfica que era fundamentada no uso de fichas padrão e em folhas soltas, permitindo o armazenamento em massa de informação. Esse processo envolvia, também, um procedimento para classificar e recuperar aquilo que se encontrava armazenado, assim como hoje ocorre no processamento por computador. A visão modular do conhecimento, possibilitada pelo princípio monográfico e pelo uso de fichas com sínteses dos documentos, permite uma interconexão de ideias e remete ao que hoje conhecemos como hipertexto. O termo hipertexto é utilizado para referir-se a um documento eletrônico que apresenta forma não linear, consistindo em uma rede de nós, que são fragmentos que possuem ligações e relacionam-se a outros, conectando os nós, permitindo, dessa forma, a navegação por diversos pontos de partida. 
Os objetos informacionais elaborados segundo o princípio monográfico assemelham-se aos registros das bases de dados e aos objetos hipertextuais, porque são unidades de informação que podem ser compreendidas isoladamente e também relacionadas a outras. Porém, se inseridos em contextos mais amplos, os objetos informacionais podem ser reinterpretados e relacionados de diversas maneiras, de acordo com o acervo de conhecimento individual e de seus objetivos (ORTEGA, 2011), o que possibilita uma visão ampla das relações entre uma informação e outra. Os documentos hipertextuais e a ideia geral do Princípio Monográfico de extrair dos documentos aquilo que é mais representativo representam um avanço ocorrido no tratamento da informação que visa à Organização do Conhecimento.

De acordo com Otlet (1937), a Documentação possui três ordens de elementos: materiais, gráficos e intelectuais. O elemento intelectual é considerado o mais importante, porque refere-se à representação da realidade ou da imaginação e para isso é essencial escolher e agrupar em uma certa ordem e, para tanto, o conjunto de documentos deve ser submetido às operações de extração e refinação do conteúdo.

\subsection{Organização e Representação do Conhecimento}

A partir da preocupação sobre como a sociedade irá organizar, consumir e produzir as informações Paul Otlet (1934) destaca, em consonância com o Tratado de Documentação o qual amplia o objeto de estudo da bibliografia, que o conhecimento pode vir a ser ordenado, adotando um conceito amplo de documentação que envolve outros produtos além do livro. Também, preocupou-se com a organização do conhecimento registrado para ser acessível de acordo com a demanda do usuário, uma vez que sua principal premissa fora compartilhar o conhecimento universal em busca da paz mundial. Além disso, no processo de criação de instrumentos para a organização, armazenamento e recuperação da informação, concentrou esforços no conteúdo da documentação, (informação, conhecimento registrado), desde a sua produção até a sua representação (FREIRE, 2006).

O conceito de Conhecimento é explanado por Barité (2001) por meio de 10 premissas, a saber: 1) é um produto social; 2) é uma necessidade social e um dínamo social; 3) o qual realiza-se a partir da informação; 4) ao ser socializado torna-se informação novamente; 5) sua estrutura e comunicação formam um sistema aberto; 6) que deve ser organizado para melhor aproveitamento tanto individual como social; 7) pode ser organizado de infinitas formas; 8) sua organização é sempre artificial, provisional e determinista; 9) registra-se sempre em documentos; expressa-se por conceitos e se organiza por meio de sistemas de conceitos, os quais podem ser organizados para fins científicos, funcionais ou de documentação; 10) as leis que regem a organização de sistemas de conceitos são uniformes e previsíveis e se aplicam 
Nesse contexto, destaca-se que os documentos se referem ao elemento fundamental delineado como "registros informacionais" (SILVA; TOGNOLI; GUIMARÃES, 2017, p. 47) e sua relevância acontece na medida em que estes proporcionam matéria prima para o trabalho da Organização e Representação do Conhecimento (ORC), que é formada por dois conceitos imprescindíveis: a Organização do Conhecimento (OC) e a Representação do Conhecimento (RC), os quais são decorrência da reunião das categorias Objeto e Ação. Sendo que Objeto é o próprio conhecimento e Ação é a atividade de organizar e representar, de gerar instrumentos, processos e produtos para 0 uso em ambientes institucionais (FUJITA, 2008). Nesse sentido, sua acepção refere-se à área dedicada ao estudo para o desenvolvimento da teoria, processos, produtos e métodos para, a partir do conteúdo do documento, vir a promover a conversão da informação em novo conhecimento.

O esforço essencial da área de Biblioteconomia e Documentação direciona-se no sentido de reunir as teorias mais significativas para construção de instrumentos de organização e recuperação em busca de uma consolidação teórico-conceitual para a OC. São nesses instrumentos que ocorre a junção da fundamentação teórica com a aplicação da teoria (FUJITA, 2001).

Barité (2012) afirma que nos últimos anos a OC vem se dedicando ao desenvolvimento de estruturas de conceito com finalidades distintas, que podem estar presentes na biblioteconomia, na arquivística e na informática, visando organizar recursos informacionais para recuperação e uso.

Para os autores Lima e Alvares (2012), a OC no seu sentido amplo sistematiza ordenadamente os assuntos. Já no seu sentido estrito, Hjørland (2008, p. 88, tradução livre, grifo nosso) citado por Silva, Tognoli e Guimarães (2017, p. 47) refere-se ao conceito como "atividades de descrição, indexação e classificação de documentos realizadas em Bibliotecas, Base de Dados e Arquivos".

A Descrição refere-se ao tratamento da informação. Neste estudo nos interessa o tratamento temático (representação temática) que aborda os aspectos intrínsecos do documento, por meio de instrumentos específicos para promover a representação condensada dos documentos (BRASCHER; CAFÉ, 2008; DIAS; NAVES, 2007; 2013). A Descrição faz a ligação entre o documento e o usuário (SILVA; TOGNOLI; GUIMARÃES, 2017).

A Indexação, segundo Chaumier (1986, tradução nossa), possui as etapas de extração de conceitos e a tradução desses conceitos, utilizandose de Linguagem Documentária. Para Souza (2011), a indexação tem como produto os índices (autor, título e assunto) ou os pontos de acesso (catálogos de assunto). De todo modo, é uma operação complexa para identificar e descrever o conteúdo do documento para a Recuperação da Informação.

A Classificação faz a ligação entre o documento e seu contexto (SILVA; TOGNOLI; GUIMARÃES, 2017) e refere-se a uma operação 
intelectual que sistematiza, agrupa, separa, hierarquiza a partir das semelhanças e diferenças para compreender o conteúdo informacional. Também é uma atividade de compreensão e representação por meio do auxílio de uma linguagem pré-estabelecida, ou seja, os sistemas de classificação. Os sistemas de classificação possuem hierarquia numérica e conceitual, organizada do geral para o específico, uma vez que as classes mais genéricas se posicionam no topo e as classes mais específicas se situam abaixo. Tem por objetivo a recuperação da informação e determinam a posição conceitual do documento no âmbito da estrutura deste sistema de classificação.

Nesse contexto, o Tratamento Intelectual da Informação (TII) representa uma área que desenvolve processos, utilizando instrumentos para gerar produtos (GUIMARÃES, 2009), propiciando o armazenamento e a recuperação da informação (GUIMARÃES; SALES; GRÁCIO, 2012). Guimarães (2008; 2009) relata que Smit (1986, p.12) refere-se ao TTI como "reunir e organizar para achar". Isto posto, os processos e instrumentos são iniciados a partir do tratamento intelectual da informação com o intuito de representar o conteúdo do documento sem perda de informação.

O TTI, como termo amplo, refere-se à análise, à descrição e à representação do conteúdo de documentos (GUIMARÃES, 2009; GUIMARÃES; SALES; GRÁCIO, 2012), desta forma a relevância do tratamento intelectual é aparente, desde a separação dos documentos seguindo pela busca de seus conteúdos.

O processo metodológico do TTI, de acordo com Kobashi (1994), representa o conteúdo de documentos e, para isso, é necessário realizar a análise, a síntese e a representação.

- Análise: ocorre por meio da leitura documental em que se extraem os conceitos que representam o conteúdo do documento. Para um melhor entendimento, Pinto Molina (1993, tradução nossa) define a Análise como um processo cognitivo de identificação de conceitos de registros documentais, por meio da leitura realiza-se uma atividade mental de recepção, percepção visual e compreensão para identificar os conceitos. Os autores Naves (2001) e Dias e Naves (2007; 2013) consideram que para a formação de conceitos utiliza-se de um processo com etapas inseparáveis por análise (consiste em separar em partes ou decompor), síntese (recompor o todo), abstração (operação de isolar sem sair do contexto para identificar se é geral ou específico), generalização (categorização dentro de uma mesma classe).

- Síntese: Pinto Molina (1993, tradução nossa) menciona que reduzir o conteúdo de um registro documental é a tarefa mais complexa que se pode realizar, uma vez que se trata da etapa que determina o assunto por meio dos conceitos selecionados, ou seja, por meio da escolha de conceitos ou palavras-chave que traduzem o conteúdo do documento.

- Representação: etapa do processo de condensação do conteúdo do documento que é representada por um sistema de símbolos, sinais, palavras, figuras, desenhos, gestos, esquemas, entre outros. 
A Representação do Conhecimento, do ponto de vista de Novo (2013), empenha-se em materializar o pensamento humano e a construção do conhecimento, ou seja, representar uma unidade de conhecimento ou o conceito.

De acordo com Fujita (2008, p. 6), a RC é compreendida por Dahlberg por meio de duas características diferentes: pela representação do conhecimento por meio de conceitos e pela representação da estrutura lógica do conhecimento, que vem a ser o resultado da atividade da OC.

Na concepção de Bräscher e Café (2008, p. 8), as estruturas conceituais produzidas no processo de "[...] modelagem do conhecimento que visa à construção de representações do conhecimento [...]" são, em síntese, aquilo que a área da Organização do Conhecimento busca. Esta se relaciona com análise do conceito e fundamenta-se na sua identificação e posicionamento em meio ao domínio investigado.

Sendo o conhecimento a matéria básica que compõe a informação, a transmissão de conhecimento para a geração de novo conhecimento é um objetivo que dá sentido ao Ciclo da Informação Documentária (ESTEBAN NAVARRO, 1999). O Ciclo Documentário tem como principais operações a coleta, o registro, o tratamento intelectual, a pesquisa e a difusão (FEITOSA, 2006). Isso porque refere-se a um conjunto de operações de tratamento dos documentos organizado como um sistema em que os documentos entram por um lado, passam por processamento e saem na forma de produtos documentários. Esses produtos são utilizados em atividades de pesquisa e retornam ao sistema na forma de novos documentos.

Realizando-se uma analogia com o Tratamento Documentário, que é realizado em arquivos, o Ciclo Documentário em unidades de informação pode ser acomodado ao arquivo (Figura 1). Neste caso, o Ciclo Documentário é apreendido como um sistema em que os documentos dão entrada no momento de sua criação ou recebimento, passam por processamento e resultam em produtos documentários (índices, inventários, guias, catálogos) que servirão à pesquisa e à Organização do Conhecimento no domínio arquivístico, visando localizar documentos específicos ou, por meio dos instrumentos gerados, conhecer o domínio ao qual se referem os documentos. 


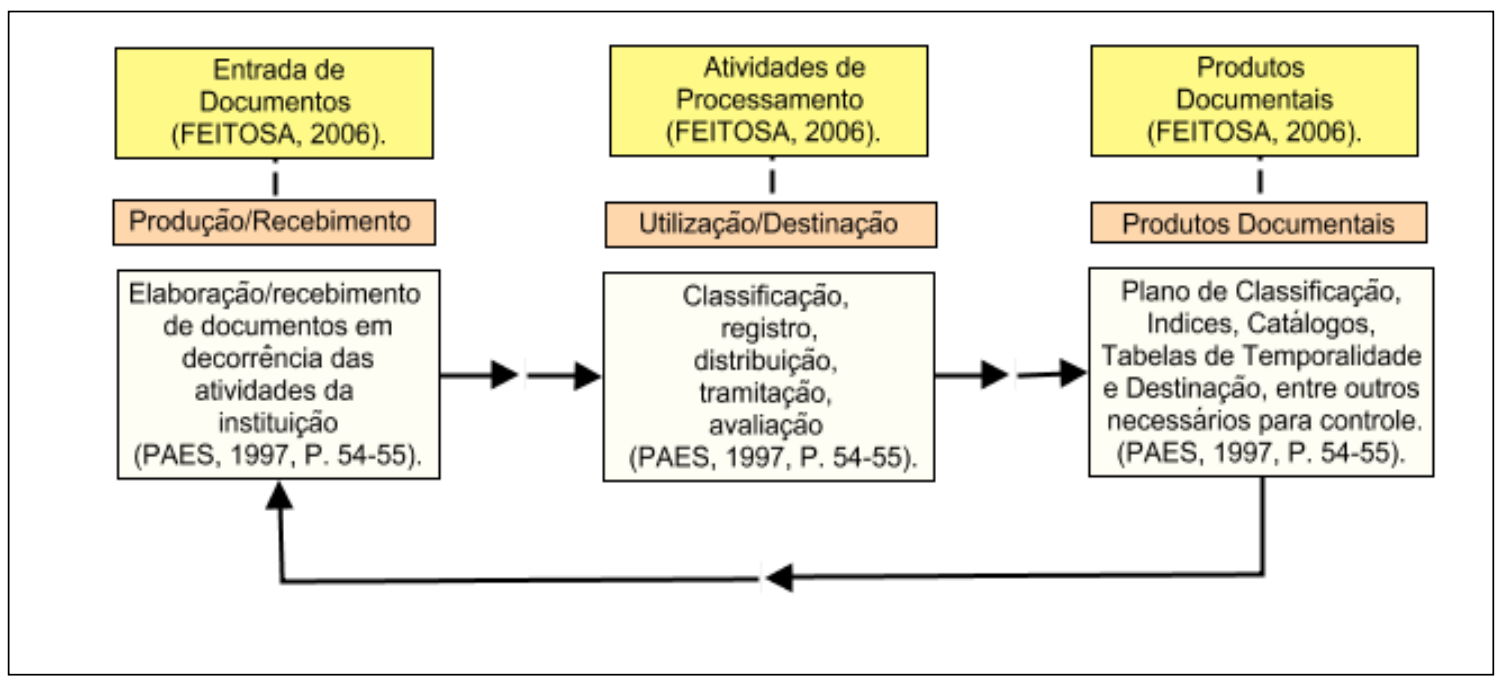

Figura 1 - Ciclo da informação documentária e sua relação com os arquivos.

Fonte: Elaboração das autoras fundamentadas em Feitosa (2006, p.19) e Paes (1997, p. 54-55).

A partir da figura 1 identifica-se que as atividades de processamento do Ciclo Documentário ocorrem no Tratamento Documentário em Arquivos durante o período de utilização/destinação, no qual os procedimentos de registro, classificação, distribuição, tramitação, avaliação são realizados, sendo que todos esses procedimentos ou processos dependem do Tratamento Intelectual da Informação, neste caso informação Arquivística.

$\mathrm{Na}$ Arquivística, o tratamento temático da informação é apreendido como um meio adicional de acesso aos documentos arquivísticos, já que a gestão documental em seus processos de classificação e descrição considera necessariamente os princípios arquivísticos de proveniência e organicidade (MEDEIROS, VITAL e BRÄSCHER, 2016). Sendo assim, o TTI aplicado à Arquivística pode cumprir a função de organizar não os documentos, mas a informação e o conhecimento neles contidos.

\subsection{Conceitos}

Para a melhor compreensão de conceito, pode-se dizer que é quando a mente cria ou compreende um significado universal, vindo a ter representações mentais das relações que ocorrem entre objetos na realidade empírica (BUFREM; GABRIEL JUNIOR, 2011).

Contemporaneamente, os estudos que tomam o conceito como objeto estão presentes na Filosofia, assim como na Linguística, na Psicologia, na Educação, nas Ciências cognitivas, na Ciência da Informação, entre outras (FRANCELIN; PINHO, 2011). Para a área da ORC, o conceito é considerado elemento básico para análise e compreensão de objetos informacionais dentro de contextos gerais ou específicos. 
Dahlberg (1978) define os conceitos como enunciados verdadeiros sobre determinado objeto, fato ou fenômeno que podem ser representados por uma expressão apropriada por meio de instrumento que expõe a codificação que forma o conceito. Podem ser verbais (palavras) ou não verbais (símbolos).

Barros (2016) menciona que para Dahlberg (1998) o conceito possui três dimensões:

\begin{tabular}{|c|c|c|}
\hline REFERENTE & TERMO & CARACTERÍSTICAS \\
\hline $\begin{array}{c}\text { É a unidade do } \\
\text { pensamento da realidade } \\
\text { observável. }\end{array}$ & $\begin{array}{c}\text { É a palavra utilizada para } \\
\text { comunicar. }\end{array}$ & $\begin{array}{c}\text { São as propriedades } \\
\text { atribuídas conceitualmente. }\end{array}$ \\
\hline
\end{tabular}

Quadro 1 - As três dimensões do conceito segundo Dahlberg (1998).

Fonte: Elaborado pelas autoras.

Estas três dimensões podem ser exemplificadas na proposição: 'É possível pensar (referente) para falar (termo) por meio de atributos (características) sobre pássaros (exemplo de conceito) '.

O conceito na dimensão de referente é a unidade do pensamento da realidade observável e os autores Barité (2001, tradução nossa; 2011, tradução nossa), Dahlberg (2007), Lara (2001), Dias e Naves (2007; 2013), Novo (2013) entendem o conceito como uma unidade do conhecimento, visto que é construído a partir das relações de afinidade com outros conceitos, conforme sua vizinhança. O conceito não pode ser considerado um elemento isolado e por isso se torna um enunciado (BUFREM; GABRIEL FILHO, 2011).

O conceito na dimensão de termo é a palavra utilizada para comunicar. De acordo com Barros (2016), o indivíduo é capaz de se fazer entender pelos seus semelhantes por meio de uma ideia bem delineada a partir de uma palavra, isso, quando é organizado sistematicamente em algum campo do saber, caracteriza-se como conceito. Nesse contexto, a palavra infere-se como unidade de comunicação e conceito, como já foi dito, unidade do conhecimento. Para uma melhor compreensão, observase que, para as palavras se tornarem conceitos, é preciso que ultrapassem a condição de unidade de comunicação e se convertam em unidade de conhecimento, e isso demanda estar no centro de determinada análise ou campo de estudos.

Para os indivíduos os conceitos são essenciais, visto que se utilizam de várias ideias subordinadas e com a ajuda da palavra, coerente e bem clara, consegue chegar a uma conclusão geral. O emprego das palavras acontece conforme seus diferentes usos e aplicações, pois remeterá ao significado da palavra expressa. Também é preciso mencionar que a comunicação colabora com o estudo, possibilitando articulações de 
conceitos vizinhos ou distantes, provendo outras formas de ver as palavras.

O conceito na dimensão de características são as propriedades atribuídas conceitualmente. Do mesmo modo, os conceitos são formados por uma combinação de características, ou seja, o conceito forma-se a partir de um processo de abstração ao selecionar propriedades de um ou mais objetos/ideias/fatos/fenômenos. O conceito é o resultado de uma proposição dentro de um domínio do saber, uma vez que o conceito se define pela posição que ocupa em alguma estrutura de conceitos.

As características referem-se como enunciado sobre determinado objeto/ideia/fato/fenômeno que corresponde a um conceito a respeito desse mesmo objeto/ideia/fato/fenômeno. Nesse sentido, as características são necessárias para o entendimento dos conceitos.

De acordo com Dias e Naves (2007, p. 63-64), o conceito é um "conjunto de características, que são os elementos dos conceitos e traduzem os atributos das coisas designadas. A característica mais geral é chamada de categoria, que é o conceito na sua mais ampla extensão".

Para exemplificar esta abordagem, que foi observada somente por Dahlberg (1978), apresentam-se os conceitos gerais e os específicos. Os conceitos gerais são objetos que possuem forma fora do espaço e do tempo. Exemplo: Universidades. Já os conceitos individuais são objetos individuais que possuem forma e espaço e são experiências comuns do cotidiano. Exemplos: Universidades Estaduais, mesa, computador, entre outros.

As ciências buscam compreender os conceitos que se expressam de diferentes formas nas diversas áreas do conhecimento, visto que se utilizam de conceitos para os saberes científicos que se aproximarem deles (BARROS, 2016). Complementando, Novo (2013) explica que os conceitos possuem relações complexas porque os conceitos se interligam de maneira interdisciplinar por meio dos contextos disciplinares. Por isso há necessidade da organização do conhecimento, dado que os conceitos não podem ser interpretados isoladamente, mas sim sob o olhar de níveis que se integram.

Assim, os autores Dahlberg (1978), Wilson (2001) e Currás (2010) consentem a forma verbal como forma de representação de conceitos. Entretanto, os mesmos autores, além de Lara (2001), também atribuem a forma não verbal como modo de representação de conceitos.

Dal'evedove (2010) e Dal'evedove e Fujita (2013) citam que para Lara (1993) a representação é construída por meio de um processo de condensação do texto e realizada por um sistema de símbolos ou sinais com o objetivo de ordenar os conceitos selecionados. Portanto, as fases de análise e síntese desconstroem o texto para que a operação da representação reconstrua o texto de maneira a facilitar a recuperação temática da informação.

\section{Metodologia}


Este estudo caracteriza-se como uma pesquisa exploratória e tem como delineamento metodológico o estudo bibliográfico.

A pesquisa exploratória torna possível estabelecer uma visão geral ou mais próxima de algum fato a ser verificado, com a intenção de desenvolver, esclarecer e/ou modificar conceitos e ideias (GIL, 2006). Justifica-se, dessa forma, por ser uma das primeiras etapas da pesquisa, familiarizando e aproximando o pesquisador do conhecimento acerca do tema.

Utiliza-se o estudo bibliográfico para "[...] conhecer e analisar as principais contribuições teóricas existentes sobre um determinado tema ou problema, tornando-se um instrumento indispensável para qualquer tipo de pesquisa" (KOCHE, 2009, p. 122), a partir de materiais já elaborados, compostos por livros, periódicos, teses, artigos científicos, entre outros, ou seja, denominados de fontes secundárias (KOCHE, 2009; GIL, 2007). Esse método vem recuperar o conhecimento científico acumulado a respeito de um problema, visto que sua finalidade é proporcionar suporte teórico e reflexivo para a pesquisa a partir de trabalhos realizados por outros pesquisadores para evidenciar a relação dos estudos bibliográficos para a representação de conceitos no tratamento intelectual da informação no âmbito da Arquivística.

\section{Análises e resultados}

Na ORC o conhecimento pode ser organizado de várias formas, "[...] pois os contextos mudam de acordo com propósitos estabelecidos para cada momento" (NOVO, 2013, p. 16). Em razão disso, o conhecimento materializa-se em forma de documentos por meio de conceitos, de maneira semelhante, ou seja, variando a forma de acordo com o propósito.

Seguindo-se o fluxo do Ciclo Documentário da Informação aplicado tanto aos Arquivos como às Bibliotecas e Centros de Documentação, o TTI ocorreria durante as atividades tratamento intelectual da informação, as quais podem vir a "facilitar e agilizar o acesso à informação, por meio da fragmentação do suporte que reorganizado proporciona a unidade do conteúdo" (SANTOS, 2006, p. 87).

Nesse sentido, destaca-se que os estudos bibliográficos fundamentam teoricamente a ORC no âmbito da Ciência da Informação, como um campo que apoia as teorias e práticas ligadas ao processo de identificação de conceitos para posterior representação e recuperação da informação para gerar conhecimento individual e social.

A ORC está conectada ao TTI em razão da subjetividade do processo e suas operações específicas. De acordo com Barité (2001, tradução nossa), ao se realizar as etapas de identificar, processar e disponibilizar o conteúdo do documento, o TTI propicia condições para efetuar as operações de representação e acesso à informação.

Paul Otlet destaca que os registros documentais possuem três elementos, sendo o mais importante o intelectual, o qual é submetido à 
operação de extração e refinação do conteúdo. Assim, os processos na ORC são amplos e complexos e, tanto na Biblioteconomia, quanto na Arquivística, o processo de identificação de conceitos reporta-se como atividade central, por meio do processo do TTI, que acontece por meio das atividades da análise, síntese e representação dos conceitos, os quais podem servir à classificação e descrição, indexação na Arquivística, bem como na Biblioteconomia e Ciência da Informação.

Também se identificou equivalências na Biblioteconomia e na Arquivística dentro do conceito estrito de OC, aproximando os procedimentos dessas disciplinas nos seguintes pontos:

- Atividades de descrição, indexação e classificação, posto que são consideradas "funções nucleares no processo de ORC" (SILVA; TOGNOLI; GUIMARÃES, 2017, p. 47).

- O trabalho de Descrição Temática é considerado um meio de Organização do Conhecimento.

- A Classificação representa uma atividade intelectual de construção de instrumento e resulta em um plano de classificação que organiza e representa em classes a OC (SILVA; TOGNOLI; GUIMARÃES, 2017).

- A Indexação gera produto como índice.

Os documentos de arquivo possuem a particularidade de serem únicos e pertencentes a um conjunto orgânico, diferentemente dos documentos bibliográficos que podem, por suas características mais ou menos unificadas, gerar códigos e normas para o tratamento padronizado dos acervos em bibliotecas. Por esse motivo, conforme Silva e Neves (2014), a representação temática da informação e, por conseguinte, os procedimentos de TTI não possuem relevância se considerar a arquivística tradicional ou custodial. No entanto, o objeto da Arquivística tem se deslocado lentamente do documento para a informação aquivística, pressupondo uma mudança de abordagem que a aproxima da Ciência da Informação, proporcionando um amplo espectro de aportes teóricometodológicos desta área.

Os instrumentos de organização em arquivos não são universalmente aplicáveis, pois sua criação observa as particularidades de cada instituição. Desta forma, cada instrumento arquivístico é construído como parte de um todo comum mantendo suas ligações orgânicas (SILVA; NEVES, 2014).

Medeiros, Vital e Brascher (2016) evidenciam a relação entre a função da descrição arquivística e a elaboração de pontos de acesso relacionados à essa função arquivística. Como ponto de vista comum à maioria dos autores, a representação de assunto é considerada como representação secundária do documento arquivístico, constituindo-se a representação por meio de funções arquivísticas (descrição e a classificação) como primária, pois fundamentam-se nos princípios arquivísticos de proveniência e organicidade.

Os instrumentos de organização em arquivos não são universalmente aplicáveis, pois sua criação observa as particularidades de cada instituição. Desta forma, cada instrumento arquivístico é construído 
como parte de um todo comum mantendo suas ligações orgânicas (SILVA; NEVES, 2014). Diferentemente do que ocorre com os instrumentos de organização arquivísticos primários a criação de instrumentos secundários fundamentados no conteúdo dos documentos concorda com a tradição bibliográfica, dedicada ao objeto e ao assunto, visando a disponibilização facilitada do acesso ao conhecimento.

\section{Considerações Finais}

Observa-se a importância dos estudos bibliográficos para fundamentar a Organização e Representação do Conhecimento com ênfase na representação de conceitos para tratamento intelectual da informação no âmbito da Arquivística. A relevância de Paul Otlet na Ciência da Informação adveio do Tratado de Documentação, que desenvolveu a análise do conteúdo dos documentos por meio da extração de termos representativos que hoje associamos ao termo conceito. Além de revelar um compromisso de natureza social com os registros documentais de modo a garantir a "permanência no tempo e portabilidade no espaço" (SMIT; BARRETO, 2002, p. 21 apud SILVA; TOGNOLI; GUIMARÃES, 2017, p. 51).

A preocupação com o acesso a documentos, com foco no conteúdo e a necessidade de unificação de procedimentos para ampliar as relações internacionais e facilitar a troca de dados entre diferentes domínios era o cerne do projeto da Bibliografia em Otlet e é uma questão essencial no mundo globalizado de hoje. O tratamento intelectual da informação arquivística necessita se adequar definitivamente à realidade póscustodial. Embora os problemas apontados por Silva e Neves (2014), tais como desconhecimento do usuário, estudos escassos em relação ao acesso e uso dos documentos, assim como das informações arquivísticas e das instituições arquivísticas, ainda persistam a proposta de observação dos conceitos em documentos valoriza o conteúdo e o tratamento intelectual da informação arquivística.

A representação temática da informação arquivística pode beneficiar-se de diversas maneiras dos preceitos do TTI para fundamentar a construção de seus próprios instrumentos (classificação, descrição, temporalidade e indexação) ou para, conforme proposto no estudo de Silva e Neves (2014), utilizar, por exemplo, uma taxonomia para apoiar a organização da informação arquivística, incorporando um instrumento que mesmo não sendo específico da Arquivística é uma ferramenta válida para evidenciar o conhecimento em arquivos.

1.1

\section{Referências}

BARITÉ, M. Organizacion del conocimiento: un nuevo marco teoricoconceptual en bibliotecologia y documentacion. In: CARRARA, K. (Org.). 
Educação, universidade e pesquisa: textos completos do III simpósio em filosofia e ciência: paradigmas do conhecimento no final do milênio. Marília: Unesp-Marília-Publicações; São Paulo: FAPESP, 2001. p. 35-60.

Organização do conhecimento e gestão da memória social. In: MAGALHÃES, G. (Org.). História e energia: memória, informação e sociedade. Saõ Paulo: Alameda, 2012. 376 p. p. 271-284.

Sistemas de organización del conocimiento: una tipologia actualizada = Sistemas de organização do conhecimento: uma tipologia atualizada. Inf. Inf., Londrina, v. 16, n. 3, p. 122-139, jan./jun. 2011. Disponível em: < www.uel.br/revistas/uel/index...

/informacao/.../9286>. Acesso em: 29 abril 2013.

BARROS, J. D'A. Os conceitos: seus usos nas ciências humanas. Petrópolis: Vozes, 2016.

BRÄSCHER, M.; CAFÉ, L. Organização da Informação ou Organização do Conhecimento? In: ENCONTRO NACIONAL DE PESQUISA EM CIÊNCIA DA INFORMAÇÃO, 9, 2008, São Paulo. Anais... São Paulo: ANCIB, 2008. Disponível em: <http://www.ancib.org.br/media/dissertacao/1835.pdf>. Acesso em: 20 out. 2012.

BRÄSCHER, M.; CARLAN, E. Sistemas de organização do conhecimento: antigas e novas linguagens. In: Robredo, J.; Bräscher, M. (Orgs.). Passeios no Bosque da Informação: Estudos sobre Representação e Organização da Informação e do Conhecimento. Brasília DF: IBICT, 2010, 335 p. Capíitulo 8, p. 147-176 Edição eletrônica. Disponível em: http://www.ibict.br/publicacoes/eroic.pdf. Acesso em: 16 março 2017.

BUFREM, L. S.; GABRIEL JUNIOR, R. F. A apropriação do conceito como objeto na literatura periódica científica em Ciência da Informação $=\mathrm{La}$ apropiación del concepto en cuanto objeto de la literatura científica en Ciencia de la Información. Inf. Inf. Londrina, v. 16, n. esp, p. 52-91, jan./jun. 2011. Disponível em: <http://www.brapci.ufpr.br/documento. php?dd0 $=0000011573 \& d d 1=9 d 7 e c>$. Acesso em: 5 abril 2014 .

CAMPOS, M. L. de A. Em busca de princípios comuns na área de representação da informação: uma comparação entre o método de classificação facetada, o método de tesauro-baseado-em-conceito e a teoria geral da terminologia. 1994. 196 f. Dissertação (Mestrado em 
Ciência da Informação) - Instituto Brasileiro de Informação em Ciência e Tecnologia, Universidade Federal do Rio de Janeiro, Rio de Janeiro, 1994.

CHAUMIER, J. Systemes d'information: marché et technologies. Paris: Enterprise Moderne, 1986.

CURRÁS, E. Ontologias, Taxonomia e Tesauros em teoria de sistemas e sistemática. Brasília: Thesaurus, 2010. cap. 3.

DAHLBERG, I. Feature. Interview with Ingetraut Dahlberg, december 2007. Knowl. Organ., v. 35, n. 2/3, p. 82-85, 2007.

. Fundamentos teóricos-conceituais da classificação. R. Bibliotecon. Brasília, v. 6, n. 1, jan./jun. 1978.

DAL' EVEDOVE, P. R. A perspectiva sociocognitiva no tratamento temático da informação em bibliotecas universitárias: aspectos inerentes a percepção profissional. 2010. 300 f. Dissertação (Mestre em Ciência da Informação) - Faculdade de Filosofia e Ciências, Universidade Estadual Paulista, Marília.

DAL' EVEDOVE, P. R.; FUJITA, M. S. L. Estudo sociocultural da comunidade discursiva do tratamento temático da informação em bibliotecas universitárias. Encontros Bibli [On-line] 2013, 18 (EneroAbril): Disponível em: <http://www.redalyc.org/articulo.oa?id= 14726166003> .Acesso em: 13 mar. 2014.

DIAS, E. W.; NAVES, M. L. Análise de assunto: teoria e prática. Brasília: Teshaurus, 2007. $116 \mathrm{p}$.

; M. L. Análise de assunto: teoria e prática. 2. ed. rev. Brasília: Briquet de Lemos, 2013. 115 p.

ESTEBAN NAVARRO, M. A. Fundamentos epistemológicos de la classificación documental. In: PINTO, M. Manual de classificación documental. Madrid: Editorial Sintesis, 1999.

FEITOSA, A. Organização da informação na web: das tags à web semântica. Brasília: Thesaurus, 2006. 132 p. 
FIGUEIREDO, N. Paul Otlet e o centenário da FID. In: Organização do conhecimento e sistemas de classificação. Brasília: IBICT, 1996. p. 14-19.

FRANCELIN, M. M.; PINHO, F. A. Conceitos na organização do conhecimento. Recife: UFPE, 2011.

FREIRE, G. H. Ciência da Informação: temática, histórias e fundamentos. Perspect. Ciênc. Inf., Belo Horizonte, v. 11, n. 1, p. 6-19, jan./abr. 2006.

FUJITA, M. S. L. Organização do Conhecimento: algumas considerações para o tratamento temático da informação. In: CARRARA, K. (Org.). Educação, universidade e pesquisa. Marília: Unesp-Marília-Publicações, 2001. p. 29-72.

- Organização e Representação do Conhecimento no Brasil: análise de aspectos conceituais e da produção científica do enancib no período de 2005 a 2007. Tendências da Pesquisa Brasileira em Ciência da Informação, v. $1, \quad$ n. 1 , $2008 . \quad$ Disponível em: http://inseer.ibict.br/ancib/index. php/tpbci/article/view/4/13. Acesso em: 13 maio 2014.

GIL, A. C. Como elaborar projetos de pesquisa. 4. ed. São Paulo: Atlas, 2007. 175 p.

2006. 206 p.

. Métodos e técnicas de pesquisa social. 5. ed. São Paulo: Atlas,

GUIMARÃES, J. A. C. Abordagens teóricas de tratamento temático da informação (TII): catalogação de assunto, indexação e análise documental $=$ Theoretical approaches on information subject treatment: subject cataloging, indexing and subject analysis. Ibersid. 2009. p. 105117. Disponível em: <www.ibersid.eu/ojs/index.php/ibersid

/article/download/3730/3491>. Acesso em: 13 maio 2013.

A dimensão teórica do tratamento temático da informação e suas interlocuções com o universo científico da International Society for Knowledge Organization (ISKO). Rev. Ibero-Am. Ciên. Inf., Brasília, v. 1, p. 77-99, jan./jun. $2008 . \quad$ Disponível em: 
<http://www.red.unb.br/index.php/ Acesso em: 14 maio 2013.

GUimARÃES, J. A. C.; SALES, R.; GRACIO, M. C. C. A dimensão interdisciplinar da análise documental nos contextos brasileiro e espanhol no âmbito da organização do conhecimento. Datagramazero (Rio de Janeiro), v. 13, n. 6, 2012. Disponível em: < http://www.dgz.org.br/dez12/Art_07.htm>. Acesso em: 13 mar. 2014.

HJØRLAND, B. J. What is Knowledge Organization (KO)? Knowledge Organization: international journal devoted to concept theory, classification, indexing, and knowledge represent ation, Frankfurt, v. 35, n. $2 / 3$, p. $86-101,2008$.

KOBASHI, N. Y. A elaboração de informações documentárias: em busca de uma metodologia. 1994. 195 f. Tese (Doutorado em Ciências da Comunicação) - Escola de Comunicações e Artes, Universidade de São Paulo, São Paulo, 1994.

KÖCHE, J. C. Fundamentos de metodologia científica: teoria da ciência e iniciação à pesquisa. 28. ed. Petrópolis, RJ: Vozes, 2009. 182 p.

LARA, M. L. G. de. O Unicórnio (o Rinoceronte, o Ornitorrinco...), a análise documentária e a linguagem documentária = The Unicorny (the Rhinoceros, the Ornithorhynchus ...), the Documentary Analysis and the Documentary Language. DataGramaZero: Revista de Ciência da Informação, Rio de Janeiro, v. 2, n. 6, dez. 2001. Disponível em: <http://www.datagramazero.org.br/dez01/F_I_art.htm>. Acesso em: 15 mar. 2011.

LIMA, J. L. de O.; ALVARES, L. Organização e representação da informação e do conhecimento. In: ALVARES, L. (Org.). Organização da informação e do conhecimento: conceitos, subsídios interdiciplinares e aplicações. São Paulo: B4 Editores, 2012. 248 p. Capítulo 1, p. 21-48.

MEDEIROS, G. M. de; VITAL, L. P.; BRÄSCHER, M. Tratamento temático da informação em documentos arquivísticos: estudo dos anais da ISKO e do GT2 do Enancib. Tendências da Pesquisa Brasileira em Ciência da Informação, v.9, n.1, jan./ago. 2016. Disponível em: < http://inseer.ibict.br/ancib/index.php/tpbci/article

/viewFile/216/307>. Acesso em: 28 mar. 2017. 
NAVES, M. M. L. Estudo de fatores interferentes no processo de análise de assunto. Perspect. cienc. inf., Belo Horizonte, v. 6, n. 2, p. 189 - 203, jul./dez. 2001. Disponível em: <portaldeperiodicos.eci.ufmg.br/index.php/pci/article/download/.../236>. Acesso em: 27 jul. 2013.

NOVO, H. F. Representação do conhecimento ou representação conceitual? Uma investigação epistemológica no âmbito da Ciência da Informação e da filosofia nas considerações de Deleuze e Guatarri. Ponto de Acesso, Salvador, v.7, n.3 ,p. 114-129, dez 2013. Disponível em: www.pontodeacesso.ici.ufba.br/index.php/revistaici/article/view/9328/693 9. Acesso em: 27 mar. 2014.

ORTEGA, C.D. Do princípio monográfico à unidade documentária: exploração dos fundamentos da Catalogação. Liinc em Revista, v. 7, n. 1, mar. $2011 . \quad$ Disponível em: <http://revista.ibict.br/liinc/index.php/liinc/article/view/402>. Acesso em: 24 jun. 2016.

OTLET, P. Documento e Documentação: discurso pronunciado no Congresso da Documentação Universal, Paris, 1937. Rio de Janeiro: Imprensa Nacional. Disponível em: <http: www.conexaorio.com/biti/otlet/index.htm>. Acesso em: 16 março 2017.

- The systematic organization of documentation and the development of the international institute of bibliography. In: RAYWARD, W. B. (Ed.). International organization and dissemination of knowledge: selected essays of Paul Otlet. Amsterdam: Elsevier, 1990. p. 173-203.

PAES, M. L. Arquivo: teoria e prática. 3. ed. Rio de Janeiro: FGV, 1997.

PINTO MOLINA, M. Análisis documental: fundamentos y procedimentos. 2 ed. rev. y aum. Madrid: EUDEMA, 1993. cap. 7, 9, 10, 11.

ROBREDO, J. Do documento impresso à informação nas nuvens: reflexões. Liinc em Revista, Rio de Janeiro, v.7, n.1, p. 19 - 42, março, 2011. Disponível em: <http://revista.ibict.br/liinc/index.php/liinc/article/viewFile/401/261>. Acesso em: 20 jan. 2017. 
SANTOS, P. de M. L. dos. O ponto de inflexão Otlet: uma visão sobre as origens da documentação e o processo de construção do Princípio Monográfico. 2006. 138 f. Dissertação (Mestrado) - Escola de Comunicações e Artes da Universidade de São Paulo, São Paulo, 2006. Disponível em: http://www.teses.usp.br/teses/disponiveis

/27/27151/tde-24092007-173121/pt-br.php. Acesso em: 16 mar. 2017.

SHERA, J. H.; CLEVELAND, D. B. History and foundations of information science. Annual Review of Information Science and Technology, Washington, CO. v.2, p. 249-275, 1977.

SILVA, F. A. P. da; TOGNOLI, N. B.; GUIMARÃES, J. A. C. Os valores éticos na organização e representação do conhecimento arquivístico. Brazilian Journal of Information Studies: Research Trends. 11:1 (2017) 44-53.

Disponível em:

http://www2.marilia.unesp.br/revistas/index.php/bjis/issue/view/377>. Acesso em: 15 fev. 2017.

SOUZA, E. D. de. Tratamento Temático da Informação: processos de análise e representação. Macéio: Universidade Federal de Alagoas, 2011. Disponível em: http://www.ichca.ufal.br/graduacao/biblioteconomia/v1/wpcontent/uploads/tratamento-analise-da-informacao.pdf. Acesso em: 03 maio 2014.

WILSON, J. Pensar com conceitos. São Paulo: Martins Fontes, 2001. 